\title{
Technetium Tc-99m Sulfur Colloid
}

National Cancer Institute

\section{Source}

National Cancer Institute. Technetium Tc-99m Sulfur Colloid. NCI Thesaurus. Code C856.

A gamma-emitting colloid used in scintillation scanning of the reticuloendothelial system (RES). After intravenous administration, technetium Tc $99 \mathrm{~m}$ sulfur colloid is phagocytized by the reticuloendothelial system and concentrated in the liver, spleen, and bone marrow; detection/localization of phagocytized gamma ray-emitting colloid is performed with a gamma-ray scintillation camera. Scintillation scanning using technetium T c 99m colloid sulfur helps determine the distribution and function of the RES and the extent to which tumor involves the RES. The RES includes cells types that can phagocytize and sequester inert particles and vital dyes; RES cell types include macrophages or macrophage precursors, specialized endothelial cells lining the sinusoids of the liver, spleen, and bone marrow, and reticular cells of lymphatic tissue and of bone marrow. 